\title{
Investigation on Current Situation of Satisfac- tion for Young Teachers with Doctorate in Uni- versity and Analysis on its Affecting Factors - Taking Guizhou Province as an example
}

\author{
Xinlan Jiang ${ }^{\text {a }}$ \\ Public Management College, Guizhou Financial University, 550025 Guiyang Guizhou, China
}

\begin{abstract}
This Investigation on satisfaction for young teachers with doctorate in 7 undergraduate universities in Guizhou is based on a questionnaire. The result shows that the employers are generally satisfied with young teachers with doctorate, and the satisfaction on "ideological spirit" is the highest, but the satisfaction on "working benefits" is the lowest. The science and engineering major has a higher satisfaction on young doctors than arts major, and the satisfaction on young doctors in provincial key universities is higher than general and local universities in the province; people in different sex, age, title and level will not affect the satisfaction on young teachers with doctorate. Based on what is mentioned above, the corresponding advice of increasing quality of doctor, reforming the motivation mode and improving the working environment is proposed.
\end{abstract}

Keyword. teacher in university; adolescent doctor; satisfaction

\section{Introduction}

Satisfaction concept is about psychology. Working satisfaction is a cognition of the staff on their work when being affected by factors such as their own physiology, psychology and ambient environment. [1] Satisfaction has been widely used on the research since mid and late 1900s, and it is mainly applied in research of econometrics, which refers to "a person's feeling status of happiness or disappointment formed by comparing a perceptible effect (or result) for one product with its desired value". Its advantage lies in "analysis and consideration of customer's demand on customer's perspective instead of interest and opinion of enterprise to improve the quality management efficiency and facilitate the enterprise development." [2]

Guizhou Province is located in the west part and, affected by history, reality and environment, its development lags behind compared with other provinces in China. The back-

\footnotetext{
a Corresponding author: jiangxinlan2006@163.com
} 
ward economy affects the educational development which reversely affects the development of social economy. The teacher factor is one of the factors that induce laggard educational development, especially highly related to the lack of high-level talents. There are mainly two channels to obtain the high-level talents in Guizhou Province; First, it's the cultivation of cultivating institutions. However, due to the laggard educational development, there's no university directly receive the support of central department in Guizhou. What's worse, the provincial cultivation of high-level doctor starts lately and has small scale. The doctoral candidate in Guizhou Province started to be cultivated in 2000. In 2013, the number of master degree candidates in Guizhou Province exceeded 5000, and the recruited number of doctoral students was 99 [3], 121 in 2014. [4] By 2015, the planned number of all recruited doctors in each university in Guizhou Province is 138 , and the planned number of master degree candidates is 5,519. Thus the planned number of doctoral student is less than the scale of university. The planned number of Huazhong Normal University is 380 , let alone the number of Wuhan University, a key university of the 985 Project, is over 1,580. [5] Second, it is the introduction that Guizhou Province is regarded as the main model in recent years. Recently, Guizhou Province introduces a considerable number of doctoral high-level talents with various measures. It introduced a total of 608 doctors in 2014, [6] most of whom are in the provincial university and make due contribution to social economic development, higher educational talents cultivation and social service in Guizhou Province, so they are like fresh troops for university. Then how about the satisfaction degree of employers on them and what are the factors affecting the satisfaction on young teachers with doctorate? The relevant research is limited, so from the perspective of employer, using empirical research method and discussing the satisfaction of employers on young teacher with doctorate may have an important value in improving the professional growth of young teacher with doctorate.

\section{Research design}

\subsection{Measurement tool}

This research uses self-prepared Questionnaire of Satisfaction on Young Teacher with Doctorate in University. This questionnaire includes 6 items in total, that is, ideological spirit, scientific research ability, academic attitude, teaching ability, social service ability and working benefits. In this research, the Cronbach's alpha factor for this questionnaire is 0.89 , with high credibility.

\subsection{Research objective}

This research selects 7 undergraduate colleges in different levels as the investigated objectives, namely Guizhou University, Guizhou Normal University, Guizhou Financial University, Guizhou Normal College, Caili University, Zunyi Normal University and Guizhou Engineering Institute of Engineering Applications. It mainly uses random sampling and group sampling. During the research, 700 questionnaires are released, in which 646 efficient questionnaires are returned in this investigation and the valid returning rate is $92.3 \%$. Basic conditions of investigated objective are shown in Table 1.

\subsection{Grading mode and data processing}


To accurately find out the satisfaction degree of employers on young teachers with doctorate, the questionnaire is designed with six-point grading scale, and each option in the questionnaire is granted with $1,2,3,4,5$ and 6 points, respectively indicating the level of being very unsatisfied, unsatisfied, basically unsatisfied, basically satisfied, satisfied and very satisfied. The higher score means higher satisfaction of respondents on the young teacher with doctorate. Data processing and statistical analysis are conducted through using SPSS17.0.

Table 1. Statistical list of basic conditions of investigated objective

\begin{tabular}{|l|l|l|l|}
\hline Item & Type & Number of people (people) & 100 percent (\%) \\
\hline \multirow{4}{*}{ Sex } & Male & 303 & 46.9 \\
\cline { 2 - 4 } & Female & 343 & 53.1 \\
\hline \multirow{4}{*}{ Title } & Below 35 & 168 & 26.1 \\
\cline { 2 - 4 } & $36-45$ & 296 & 45.8 \\
\cline { 2 - 4 } & Above 46 & 182 & 28.1 \\
\hline \multirow{5}{*}{ Type } & Professor & 96 & 14.9 \\
\cline { 2 - 4 } & Assistant Professor & 291 & 45.0 \\
\cline { 2 - 4 } & Lecturer or below & 259 & 40.1 \\
\cline { 2 - 4 } & Provincial key university & 219 & 33.9 \\
\cline { 2 - 4 } & Provincial regular university & 179 & 27.7 \\
\cline { 2 - 4 } & Local university & 248 & 38.4 \\
\hline \multirow{5}{*}{ Level of staff } & Middle-level cadre & 21 & 55.4 \\
\cline { 2 - 4 } & Regular teacher & 358 & 41.3 \\
\cline { 2 - 4 } & Management staff & 267 & 46.1 \\
\hline \multirow{3}{*}{ Major } & Arts major & 348 & \\
\cline { 2 - 4 } & Science and engineering major & 298 & \\
\hline
\end{tabular}

\section{Result and analysis}

\subsection{Current situation of overall satisfaction of employer on free normal stu- dents}

First, this research makes an overall analysis on the satisfaction of employer on young teacher with doctorate. Based on what is mentioned above, it discusses the relevant factors that may affect the satisfaction on young teachers with doctorate, including sex, age, title, major, type of school, staff in different level and so on.

(1) Conditions of overall satisfaction. The result is shown in Table 2.

Table 2. Overall satisfaction on young teacher with doctorate

\begin{tabular}{llll}
\hline & Frequency & Percentage & Accumulative percentage \\
\hline Very unsatisfied & 5 & 0.8 & 0.8 \\
Unsatisfied & 12 & 1.9 & 2.7 \\
Basically unsatisfied & 23 & 3.6 & 6.3 \\
Basic satisfied & 208 & 32.2 & 38.5 \\
Satisfied & 336 & 52.0 & 90.5 \\
Very satisfied & 62 & 9.5 & 100.0 \\
Total & 646 & 100.0 & \\
\hline
\end{tabular}


The average score of satisfaction of respondents on young teacher with doctorate is 4.62 , with standard deviation 7.22; the highest score is 6 , and lowest 1 . The overall satisfaction of employer on young teacher with doctorate is relatively high.

As seen from Table 2, among 646 respondents that participated in the investigation, only 5 people gave answer of "very unsatisfied", accounting for just $0.8 \% ; 12$ people gave answer of "unsatisfied", accounting for just $1.9 \% ; 23$ people gave answer of "basically unsatisfied", accounting for $3.6 \%$; 336 people gave answer of "satisfied" , accounting for $52 \%$. As known from accumulative percentage, the proportion of answers that are "satisfied" and "very satisfied" is $61.5 \%$, and the proportion of answers that are "very unsatisfied", "unsatisfied" and "basically unsatisfied" is only 6.3\%. As seen from the percentage, the overall satisfaction of employer on young teacher with doctorate is relatively great.

(2) Basic conditions in each dimension. This research adds up the average score in 6 dimensions in the satisfaction questionnaire of young teachers with doctorate, where the average score of satisfaction on "ideological spirit" about young teachers with doctorate is 5.18 ; satisfaction on "scientific research ability" is 4.49 ; satisfaction on "teaching ability" is 4.69; satisfaction on "academic attitude" is 4.81; satisfaction on "social service ability" is 4.32 ; satisfaction on "working benefits" is 4.22 . The result shows the satisfaction on "ideological spirit" of employers about young teachers with doctorate is the highest, but the satisfaction on "working benefits" is the lowest. In addition, satisfactions in each dimension that are arranged in high-to-low order are respectively academic attitude, teaching ability, scientific research ability and social service ability.

\subsection{Analysis on affecting factor of satisfaction assessment for young teacher with doctorate}

(1) Sex $T$ inspection is conducted by taking the sex as an independent variable and the satisfaction on young teacher with doctorate as a dependent variable. The result shows the average score of male's satisfaction on young teacher with doctorate $(\mathrm{M}=4.61, \mathrm{SD}=0.685)$ is not significantly different from that of female's $(\mathrm{M}=4.63, \mathrm{SD}=0.691), \mathrm{t}(463)=-0.07$, $\mathrm{p}>0.05$.

(2) Age One-way ANOVA is conducted by taking the age as an independent variable and satisfaction on young teacher with doctorate as a dependent variable. The result shows the satisfactions of below $35(\mathrm{M}=4.66, \mathrm{SD}=0.758), 36-45(\mathrm{M}=4.61, \mathrm{SD}=0.761)$ and above $46(\mathrm{M}=4.58, \mathrm{SD}=0.692)$ in age are not significantly different, $\mathrm{F}(2,463)=0.35$, $\mathrm{p}>0.05$.

(3) Title One-way ANOVA is conducted by taking the title as an independent variable and the young teacher with doctorate as a dependent variable. The result shows the satisfactions of professor level $(\mathrm{M}=4.64, \mathrm{SD}=0.706)$, assistant professor level $(\mathrm{M}=4.59, \mathrm{SD}=0.752)$ and lecturer level and below $(\mathrm{M}=4.63, \mathrm{SD}=0.713)$ on young teacher with doctorate are not significantly different, $(2,463)=0.58, \mathrm{p}>0.05$.

(4) Staff in different levels

Table 3. Difference of mean of satisfaction on young teacher with doctorate for staff in different levels

\begin{tabular}{llll}
\hline Type of level & $\mathrm{N}$ & Mean & Standard deviation \\
\hline Middle-level leader & 21 & 4.725 & 0.726 \\
Regular teacher & 358 & 4.572 & 0.711 \\
Management staff & 267 & 4.598 & 0.713 \\
\hline
\end{tabular}

The result shows that in the assessment of staff in different levels, the means of satisfaction on young teacher with doctorate is different, but not that serious. The satisfaction on 
middle-level cadre is the highest, namely 4.725 points, which is followed by 4.598 points for management.

It is found from the variance inspection that there's no significant difference of overall satisfaction of employers in assessment of staff in different levels (See Table 4).

Table 4. Variance analysis

\begin{tabular}{llllll}
\hline & Quadratic sum & $\mathrm{df}$ & Mean square & $\mathrm{F}$ & Significance \\
\hline Between groups & 11.321 & 3 & 3.774 & 1.465 & .182 \\
In the group & 182.826 & 288 & .635 & & \\
Total & 194.147 & 291 & & & \\
\hline
\end{tabular}

(4) Type of school. The author divides 7 universities in this research into provincial key universities (Guizhou University, Guizhou Normal University), provincial regular universities (Guizhou Financial University, Guizhou Normal College) and local universities (Caili University, Zunyi Normal University and Guizhou Engineering Institute of Engineering Applications), and compares the satisfactions of young teachers with doctorate in different types of universities with variance analysis. The result shows that there's a significant difference in satisfaction on young teacher with doctorate in three types of universities, $\mathrm{F}=5.024, \mathrm{p}<0.05$ (as shown in Table 5 and Table 6). Satisfaction on young teachers with doctorate in local universities $(\mathrm{M}=4.561, \mathrm{SD}=0.692)$ is significantly lower than those in provincial key universities $(\mathrm{M}=4.712, \mathrm{SD}=0.787)$ and provincial regular universities $(\mathrm{M}=4.673, \mathrm{SD}=0.736)$. This may be caused by two factors. First, it is the geographical advantages of provincial universities. They have better facilities and obvious advantages in talent's cultivation such as discipline and teacher's development platform; second, the provincial universities have a higher requirement on inspection of comprehensive quality for young doctors when introducing the doctors compared to local universities.

Table 5. Difference of mean of satisfaction on young teacher with doctorate in different types of schools

\begin{tabular}{llll}
\hline Type & $\mathrm{N}$ & Mean & Standard deviation \\
\hline Provincial key university & 219 & 4.712 & 0.787 \\
Provincial regular university & 179 & 4.673 & 0.736 \\
Local university & 248 & 4.521 & 0.692 \\
\hline
\end{tabular}

Table 6. Variance analysis

\begin{tabular}{llllll}
\hline & Quadratic sum & $\mathrm{df}$ & Mean square & $\mathrm{F}$ & Significance \\
\hline Between groups & 16.618 & 4 & 4.152 & 5.024 & .031 \\
In the group & 158.218 & 279 & .568 & & \\
Total & 174.386 & 282 & & & \\
\hline
\end{tabular}

Note: * indicates the significance in level of 0.05. It's the same for Table 8 and Table 10 below.

(6) Disciplinary nature This research uses $\mathrm{T}$ inspection to compare the satisfaction of respondents in science and engineering major and arts major on young teacher with doctorate. The result shows that the satisfaction of respondents in science and engineering major on young teacher with doctorate $(\mathrm{M}=4.72, \mathrm{SD}=0.769)$ is significantly higher than those who in arts major $(\mathrm{M}=4.501, \mathrm{SD}=0.715), \mathrm{t}(463)=-2.02, \mathrm{p}<0.05$. It means the disciplinary nature will affect the satisfaction on young teacher with doctorate. This may be caused by the fact that humanities and social science focus on speculative and thinking ability, while the science and engineering requires frequent experiments, which are easily for people to 
see its research findings and tend to have obvious working benefits, so their satisfaction will be great.

\section{Research conclusion and advice}

This research investigates the current situation of satisfaction on young teacher with doctorate and its affecting factor. The result shows, the overall situation of satisfaction on young teacher with doctorate is good. It indicates that the employer holds a positive attitude and emotion for young teacher with doctorate. It is found from further analysis that disciplinary nature and types of schools have a significant impact on satisfaction about young teacher with doctorate, but sex, age, title and different staff will not affect the satisfaction on young teacher with doctorate. Therefore, we propose the following advice:

1) Increase the quality of introduced doctor and everyone's recognition for doctors

The research result shows that the employers are generally satisfied with young teachers with doctorate, and the satisfaction on "ideological spirit" is the greatest, but the satisfaction on "working benefits" is the lowest. Furthermore, the satisfaction of local university is lower than that of provincial university. So far, Guizhou Province has released a series of preferential policy to introduce high-level talents, and determines indexes for the annual number of introduced doctors in each unit and Dizhou City, which induces a lack of comprehensive inspection for the doctors, especially in universities in Dizhou City where they just take the completion of the index as the priority. Simplify the introduction procedure and directly introduce the people with doctoral degree, which causes the fact that some doctors have problems in teaching and man-machine communication after entrance, which affecting people's assessment on doctors. In the future procedure of introduction, we should focus on strict inspection of each link in the introduction and introduce high-quality doctors necessary for university development.

2) Reform the motivation mode to have young teacher with doctorate devote themselves in teaching, scientific research and social service.

Currently, the provincial university basically implements the regulations of assistant professor preference in previous three years after entrance for doctors no matter what their performances are, and the motivation policy such as bonus policy in some universities cannot has a positive effect on young teacher with doctorate, so the doctoral teacher has no strong development awareness, which causes low working benefits and low satisfaction on them. In the future work, we should wield the potential of young teacher with doctorate, reform the motivation policy and grant bonus for doctors to make outstanding contributions to teaching, scientific research and social service for university.

3) Create an excellent professional development platform for rapid growth of young teacher with doctorate

Affected by natural, historical and geographical factors, Guizhou Province has a laggard social economy, which directly affects the educational investment and cultivation and introduction of high-level talents. After the young teachers with doctorate enter the university, the school shows insufficient care for professional development of doctors and fails to provide excellent disciplinary construction, continuing education and disciplinary development platform, which makes some doctoral teachers upset in working for the university and directly affects the original intention of introducing the doctors. In the next work, it is required for each unit to facilitate the construction of disciplines platform and continuing education training for young teacher with doctorate and provide an excellent development platform and space for them.

\section{Acknowledgement}


Fund project: Periodical results from "Research on Modern University System Based on Academic Professional View" of Annual Project of 2014 National Social Science Foundation (GN: 14BGL126)

\section{References}

1. Hoppock R. Job Satisfaction [M]. New York: Harper \& Brothers Publishers, 1935.

2. Xiao, C.L., Liu, C.J. Model of Customer Satisfaction and its Application in Human Resources Management in University [J]. Network Wealth, 2008 (6).

3. 2013 National Recruitment Plan for Postgraduate http://kaoyan.eol.cn/html/ky/taiwan/zs2014.shtml (2013-04-15)

4. Notice of 2014 National Recruitment Plan for Postgraduate by Ministry of Education and NDRC. JF[2014] No. 3.

5. http://www.moe.edu.cn/publicfiles/business/htmlfiles/moe/s3011/201405/169460.html (2014-04-29).

6. Release of 2015 National Recruitment Plan for Postgraduate. China Graduate Entrance Exam Website http: //www.chinakaoyan.com/info/article/id/75771.shtml. (2015-04-29)

7. Guizhou Provincial Party Organization Department. Guizhou Talents Work Communication. http://www.gzzzb.gov.cn/default.aspx (2014-03) 